\title{
Apnea Monitor Using Pulse Oximetry with Tactile Stimulation to Reduce Respiration Failure
}

\section{Levana Forra Wakidi', I Dewa Gede Hari Wisana', Anita Miftahul Maghfiroh¹, Nur Azizah", and Vijay Kumar Sharma ${ }^{2}$}

${ }^{1}$ Department of Electromedical Engineering, Poltekkes Kemenkes Surabaya, Indonesia

${ }^{2}$ Shyam Lal College University of Delhi, GT Road, near Metro Sation Welcome, Dwarkapuri, Shahdara, Delhi, 110032, India

Corresponding author: Levana Forra Wakidi (e-mail: lep.forra@gmail.com).

\begin{abstract}
Respiratory failure (apnea) often occurs in premature babies, and this should be avoided because it causes low oxygen concentrations in the blood. Therefore, this can damage brain function and lead to death. Apnea is characterized by a decrease in oxygen saturation ( $\mathrm{SpO} 2)$. The purpose of this study was to design an apnea monitor that was detected with $\mathrm{SpO} 2$ parameters, alarms, and vibrating stimulation. This study uses infrared and red LEDs that emit light through the surface of the finger and is detected by a photodiode sensor. This light signal will be converted into an electrical signal and calculated by Arduino to determine the patient's $\mathrm{SpO} 2$ and $\mathrm{BPM}$ values. If the $\mathrm{SpO} 2$ value drops $5 \%$ within 5 seconds from the baseline, the device will indicate apnea has occurred, and the vibrating motor is working. $\mathrm{SpO} 2$ signals and alarms are sent to the nurse station computer via Bluetooth HC-05. The device was calibrated with a SpO2 calibrator, and the measurement results were compared with a BION pulse oximetry brand. The results of the instrument measurement on two subjects on the $\mathrm{SpO} 2$ parameter showed an error value of $2 \%$, and the BPM parameter obtained an error value of $4.54 \%$. Testing the BPM parameter using a calibrator at the 30 and 60 BPM settings shows an error value of $0 \%$, and at the $120 \mathrm{BPM}$ setting, the error value is $0.01 \%$. The vibrating motor to stimulate the baby's body when apnea occurs is functioning correctly. The results showed that measurements using subjects tended to have high error values due to several factors. This research can be implemented on patient monitors to improve patient safety and reduce the workload of nurses or doctors.
\end{abstract}

INDEX TERMS Apnea, Apnea Monitor, SpO2, Finger Sensor, Tactile Stimulation.

\section{INTRODUCTION}

A premature baby usually has a normal physical appearance, but the various systems in the body are not fully developed, for example, the respiratory system, which causes the possibility of respiratory arrest or apnea in premature babies [1],[2]. The incidence of apnea was inversely correlated with gestational age and birth weight, occurring in $7 \%$ of neonates born at 34 to 35 weeks of gestation, $15 \%$ at 32 to 33 weeks of gestation, $54 \%$ at 30 to 31 weeks, and almost all infants born at $<29$ weeks of gestation or $<1,000 \mathrm{~g}$ show symptoms of apnea [3].
Prolonged respiratory failure leads to low oxygen concentrations, resulting in brain damage and death [4]. Some studies monitor apnea using one or two physiological signals such as an ECG, EEG, pulse oximetry, snoring, or nasal airflow [5],[6]. An oximeter signal indicates oxygen saturation in the blood, which can identify apnea [7]. The value of oxygen concentration in normal conditions is generally between $95 \%-100 \%$, but individuals who live at higher elevations may have a lower normal level of oxygen saturation. Oxygen saturation values in newborns above $88 \%$ are still considered normal, in the first minute of the baby's 
birth, the $\mathrm{SpO} 2$ is $71 \%$, and every one minute, it will increase up to the tenth minute to $98 \%$, in premature babies, the oxygen saturation level is $91 \%$ lower $-97 \%$ within normal limits [8]. Pulse oximetry devices are usually calibrated in the $70 \%-100 \%$ range with an accuracy of 2\%-4\% [9]. Apnea is a condition where there is the cessation of airflow in the respiratory tract for about 10 seconds to 45 seconds during sleep [10]. Apnea causes cessation of nasal airflow for at least ten seconds. This is due to desaturation or a $3 \%$ decrease in oxygen from baseline or baseline levels [11]. A decrease of more than $90 \%$ of tidal volume for more than 10 seconds, accompanied by a decrease in oxyhemoglobin saturation of more than $3 \%$ or ending with awakening from sleep, is called apnea [12]. The American Academy of Sleep Medicine (AASM) states that the patient's condition is said to be apnea. If there is a decrease in oxygen levels of more than $3 \%$ or a reduction in airflow of more than $30 \%$, the apnea detection method is 5\% to replace the $3 \%$ decrease in oxygen and 5 seconds as a substitute for time. than 10 seconds [13]. Alice S. L. Ng et al. tried the $\mathrm{SpO}_{2}$ parameter to detect apnea events in addition to using the usual pulse oximeter [14]. Newborn care guidelines state that if the newborn is not breathing adequately (after the body has been drained and the mucus has been sucked in), it should be given brief tactile stimulation. Tactile stimulation should be done gently and carefully by rubbing the baby's back, flicking the soles of the baby's feet once or twice [15]. If the infant continues to have difficulty breathing, immediately initiate active ventilation of the infant by administering nasal oxygen. The excess use of $\mathrm{SpO}_{2}$ can provide the amount of oxygen delivered to the tissues every minute or known as oxygen delivery [16]. Thus, the use of the $\mathrm{SpO}_{2}$ measurement results can be used as a reference in determining the amount of oxygen that needs to be given to patients, this will make it easier for doctors and nurses to determine the administration of oxygen in nasal oxygen. Oxygen saturation has a positive correlation with the amount of oxygen given, meaning that the higher the oxygen level given, the oxygen saturation level will also increase. [16].

In 2006, Alice S. L. Ng et al. researched pulse oximetry or $\mathrm{SpO}_{2}$ to detect apnea in patients, and the $\mathrm{SpO}_{2}$ sensor is easy to apply to homecare scale treatments. However, this tool only gives an alarm without being equipped with further treatment if an apnea event occurs. In 2011, Majdi Bsoul et al. researched apnea detection tools in real-time using a single lead ECG with fairly accurate results [17]. However, according to Gaspar Gonzalez-Briceno, medical equipment that is directly connected to the patient can cause micro shock and to overcome it requires additional, more complicated instrumentation [18]. Shamma Alqassim et al., in 2012, designed a real-time apnea detection system using a mobile phone so that it can be used on a homecare scale. However, this system is prone to false alarms [19]. In 2016 research Diana Lucia Dorantes Olvera et al. about the apnea detection device using a camera, but installing the camera is relatively difficult and prone to false alarms [20]. Yin-Yan Lin et al. in 2017 examined the symptoms of apnea using a piezo-electric sensor and stated that the accuracy of using a piezo-electric is better than that of a flex sensor, but this sensor is too sensitive to movement [21]. In 2019, I Dewa Made Wirayuda made an apnea monitor equipped with Bluetooth and displayed it on an android phone application. The measurement of apnea in this study uses a flex sensor whose value changes easily if the sensor on the belt shifts. Furthermore, the output in this device is only displayed on the nurse call without any feedback from the device [22].

Based on the weaknesses and limitations of previous studies, the purpose of this study is to make an apnea monitor device that detects oxygen saturation with output in the form of $\mathrm{SpO}_{2}, \mathrm{BPM}$ signals, alarm indicators, equipped with vibrating stimuli as a substitute for tactile stimulation in infants if apnea occurs.

This article consists of five sections, section I contains an introduction, section II explains materials and methods, section III is the results obtained, section IV is a discussion, and section $\mathrm{V}$ contains the conclusions.

\section{MATERIAL AND METHOD}

\section{A. RESEARCH DESIGN}

This study resulted in the design of an apnea monitor that can detect oxygen saturation $\left(\mathrm{SpO}_{2}\right)$ and heart rate per minute (BPM) equipped with alarm indicators and vibrating stimuli as a substitute for tactile stimulation in infants in the event of apnea. The results of the study have been tested and measured on adult subjects with criteria aged 15-21 years, and data sampling is taken randomly.

\section{1) TOOLS AND MATERIALS}

This design uses a finger sensor, as shown in FIGURE 1, to detect the patient finger's heart rate per minute (BPM). The components used include the Atmega328 microcontroller, Op-Amp (IC LM358) as a filter, multiplexer (IC 4051) and amplifier to process $\mathrm{SpO} 2$ and BPM signals, a vibrating motor as a tactile stimulus, a computer as a display of measurement results, and Bluetooth $\mathrm{HC}-05$ to transmit data from the microcontroller to the computer. The program used for the microcontroller is Arduino (Version 1.8.2).

\section{2) RESEARCH DESIGN}

This study measures the output of the filter circuit using an oscilloscope by providing the input frequency and amplitude through a function generator. This measurement is to test the performance of the filter circuit to match its characteristics. Researchers also measured oxygen saturation $\left(\mathrm{SpO}_{2}\right)$ and heart rate per minute (BPM) in the human body at random by comparing the measurement results with the BION Pulse Oximetry tool.

\section{B. DIAGRAM BLOCK}

The block diagram of this research is as shown in Figure 2, namely the $\mathrm{SpO}_{2}$ and BPM parameters. As shown in Figure 1 , the finger sensor consists of an Infrared LED and an LED Red lamp that emits light past the fingertip, then the remaining light penetrated will be received by the photodiode. This light signal is split back into electrical 
signals for LEDs, Red lamps, and Infrared by a multiplexer. The output of the multiplexer circuit then goes to the filter circuit and is processed by the ATmega328 into $\mathrm{SpO}_{2}$ and BPM data. $\mathrm{SpO}_{2}$ data is used to monitor the condition of apnea in patients; if there is apnea, the ATmega328 will activate an alarm and vibrating motor as a substitute for tactile stimulation. $\mathrm{SpO}_{2}, \mathrm{BPM}$, and alarm data will be sent using Bluetooth HC-05 from the device to be displayed on the computer.

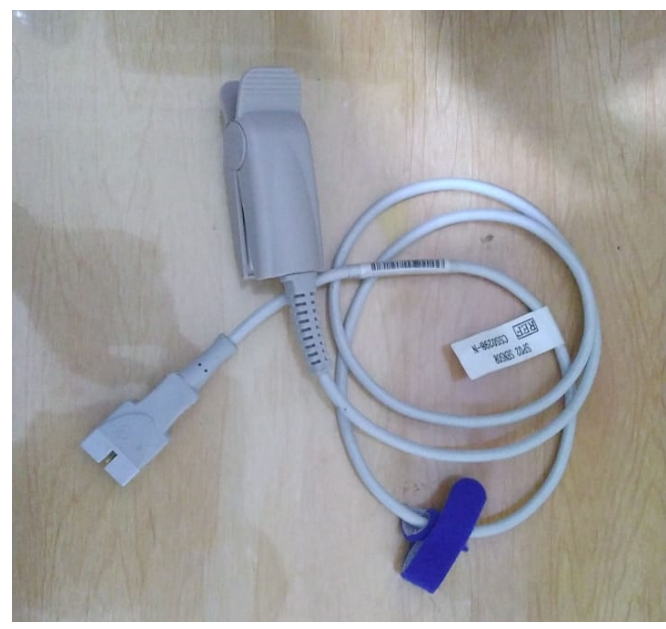

FIGURE 1. Finger sensor

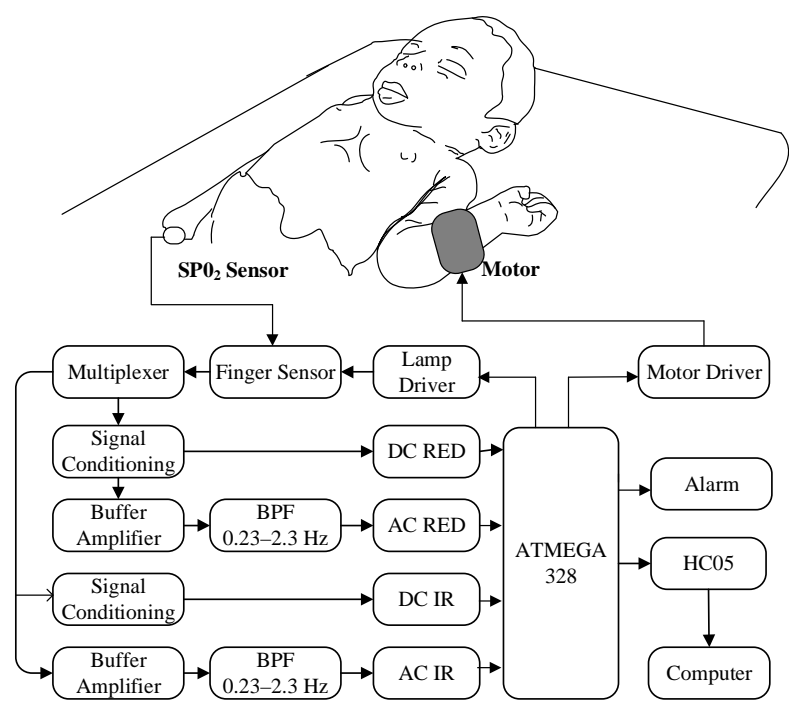

FIGURE 2. Diagram Block

\section{FLOW CHART}

In this study, the flow chart of the Arduino program, as shown in FIGURE 3. FIGURE 4 shows a flow chart for reading data on a computer. When the tool is working, the Arduino program will start the initialization process and generate pulses to turn the Infrared and LEDs Red lamp alternately and quickly. Furthermore, Arduino will read the signal. Further, the signal was processed by the filter circuit to calculate the $\mathrm{SpO}_{2}$ and $\mathrm{BPM}$ values. If the $\mathrm{SpO}_{2}$ parameter shows symptoms of apnea, the device will turn on the vibrating motor to provide tactile stimulation. The results of data processing will be sent by Bluetooth and displayed to the computer.

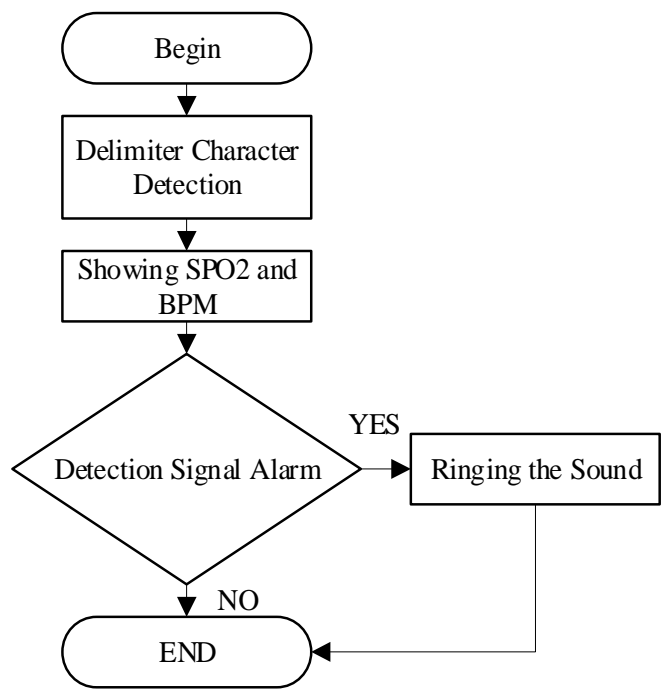

FIGURE 3. Flowchart Program on computer

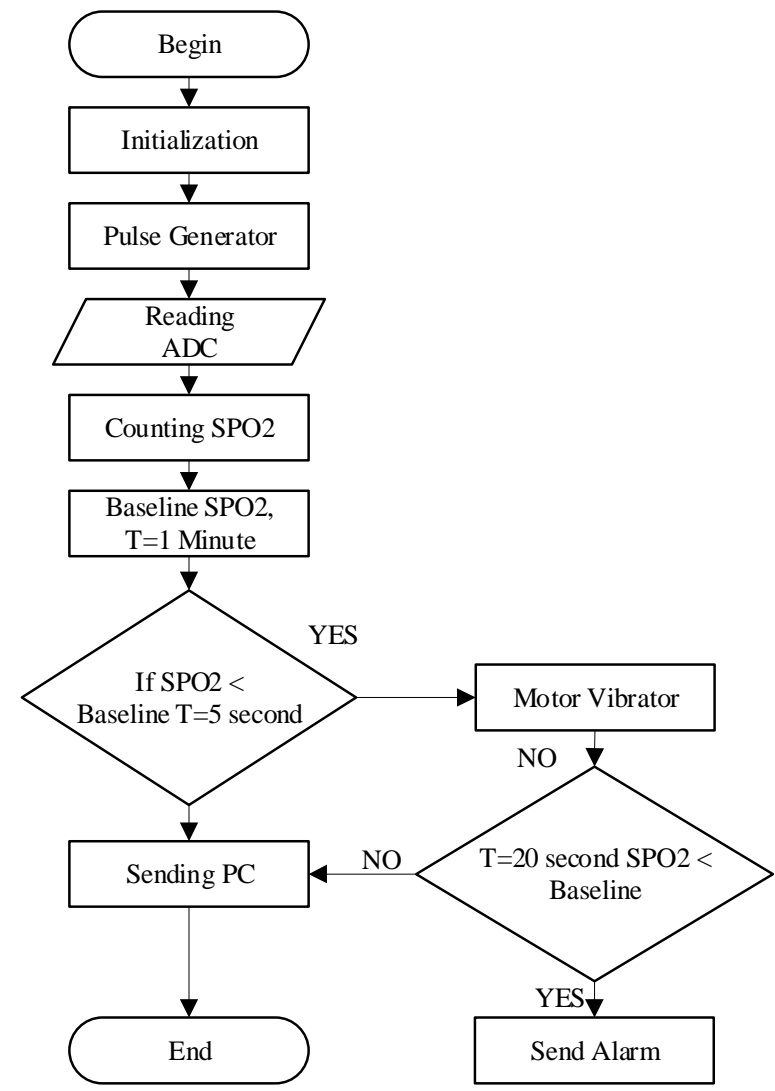

FIGURE 4. Flow chart Arduino Program

The flow chart program on the computer module uses serial communication to send digital data from Bluetooth to computer Bluetooth. Digital data from measurements of oxygen saturation $\left(\mathrm{SpO}_{2}\right)$ and heart rate per minute (BPM) are delimited by letter characters. The program on this computer is also made to activate the alarm in case of apnea. 


\section{ANALOG CIRCUIT}

This device consists of an analog circuit as depicted in FIGURE 5, namely a Band Pass Filter circuit that functions to obtain a $\mathrm{SpO}_{2}$ signal from the finger sensor.

\section{1) BANDPASS FILTER}

The Band Pass Filter circuit consists of a High Pass Filter and a Low Pass Filter with a cut-off frequency of $0.23 \mathrm{~Hz}-$ $2.3 \mathrm{~Hz}$. The output of this circuit amplifies the signal from the Non-inverting Amplifier circuit by 68 times.

\section{2) H BRIDGE}

The $\mathrm{H}$ Bridge circuit in Figure 6 has two inputs to turn on the Infrared and LEDs red lamp alternately. If inputs A and B are logic low, both the Infrared and LEDs red lamp will turn off. If input $A$ is high and input B is low, the LEDs red lamp will light up, and the Infrared will be off. If input A is logic Low and Input B is logic High, the Infrared will light up, and the LED red lamp will turn off.

\section{3) MULTIPLEXER}

The multiplexer circuit (FIGURE 7) functions to separate the signal from the Infrared and the signal from the LEDs red lamp. This circuit has one input, two outputs, and two controls. When input $\mathrm{A}$ is logic high, and input $\mathrm{B}$ is logic low (LEDs red lamp is on), the photodiode input will be connected to pin X1. Meanwhile, when input A is logic low and input $\mathrm{B}$ is logic high (Infrared is on), the photodiode input will be connected to pin $\mathrm{X} 2$.

\section{4) MICROCONTROLLER}

The microcontroller circuit shown in FIGURE 8 is used to process the output from the sensor, turn on the vibrating motor, and send data via Bluetooth. The output of the LED's red lamp signal is connected to A1. Moreover, the output of the Infrared signal is connected to the A2 of the Microcontroller.

\section{5) BLUETOOTH MODULE}

The Bluetooth module used in this device is type HC-04 to send data from sensor readings to a computer. The Bluetooth module is connected to the microcontroller by connecting the TX pin of the microcontroller to the Bluetooth $\mathrm{RX}$ pin and vice versa. The microcontroller's RX pin is connected to the Bluetooth TX pin. Bluetooth pin configuration with a Microcontroller can be seen in Figure 9.

\section{RESULT}

In this study, finger sensors were placed on patient's index finger at the fingertips to measure blood oxygen saturation levels $\left(\mathrm{SpO}_{2}\right)$ and heart rate per minute (BPM). Researchers also compared the measurement results using pulse oximetry (BION).

\section{A. DEVICE DESIGN}

The analog and digital parts of the device are shown in FIGURE 2. The analog part is a filter circuit consisting of two LM358 (Op-Amp) which each unit consists of two Op-Amps, resistors, and capacitors. The digital part consists of a microcontroller of Atmega328 as a system controller, a vibrating motor, an $\mathrm{H}$ Bridge circuit as an Infrared flame regulator, and an LED Red lamp. The digital part consists of a Bluetooth module HC-05, which is used to send data from the microcontroller to the computer.

\section{B. THE ARDUINO PROGRAM}

The Arduino program was developed to generate pulses and ADC readings. The program is shown in SNIPPET CODE 1. Moreover, the program to calculate the $\mathrm{SpO} 2$ value is shown in SNIPPET CODE 2. Further, the program to calculate BPM is shown in SNIPPET CODE 3, the program to send it to a computer via Bluetooth is shown in SNIPPET CODE 4 , and the program to activate the vibrating motor and the alarm is displayed in program 5

SNIPPET CODE 1 below serves to turn on and turn off Infrared. Input $A$ and input $B$ on the $\mathrm{H}$-bridge circuit are given alternately low logic and high logic with a duration of $1 \mathrm{~ms}$ so that the LEDs Red lamp and Infrared can light up alternately as well. When the LED Red lamp is on, ADC 1 will read the input while ADC 2 will read the input from the filter circuit when the Infrared is on.

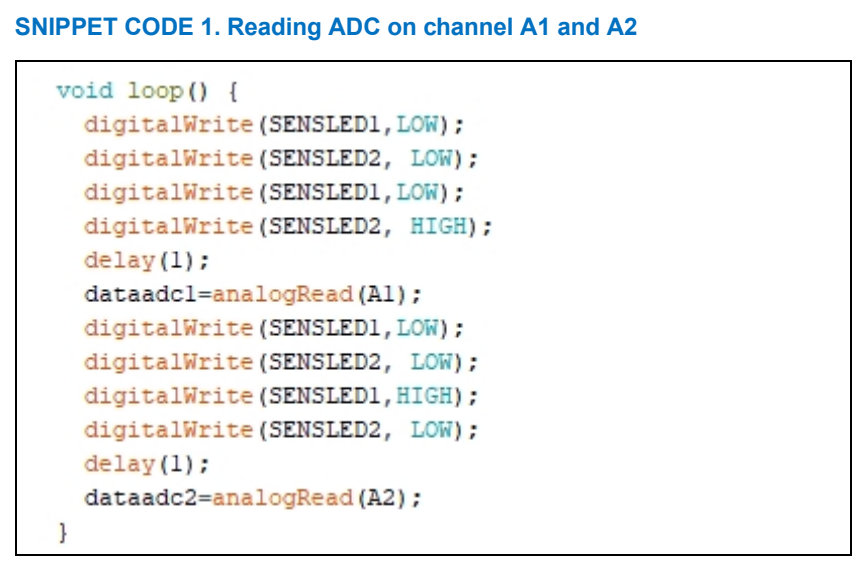

SNIPPET CODE 2. Calculate the IR and photo diode signal

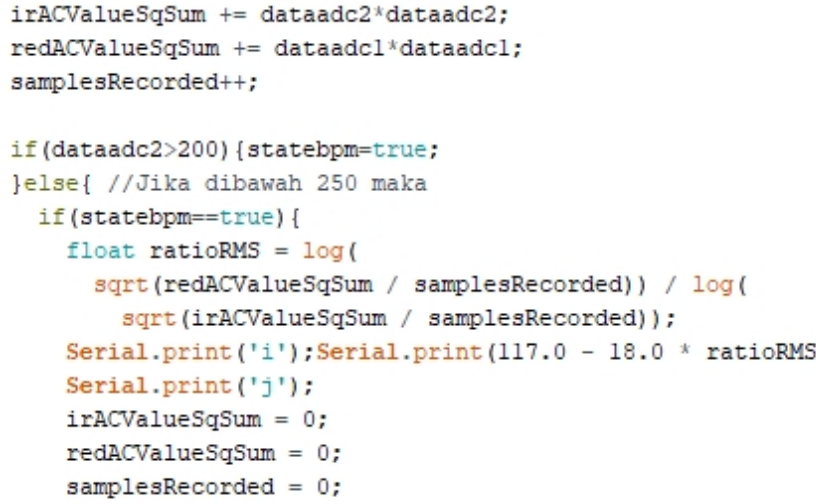

SNIPPET CODE 2 serves to calculate the value of $\mathrm{SpO}_{2}$. $\mathrm{SpO}_{2}$ value is obtained from the average signal (RMS) squared. The signal from the LED Red lamp is then divided by the signal from the Infrared and sent to the computer. $\mathrm{SpO}_{2}$ values are sent to the computer separated by sending the characters $\mathrm{i}$ and $\mathrm{j}$. 
SNIPPET CODE 3. The BPM conversion

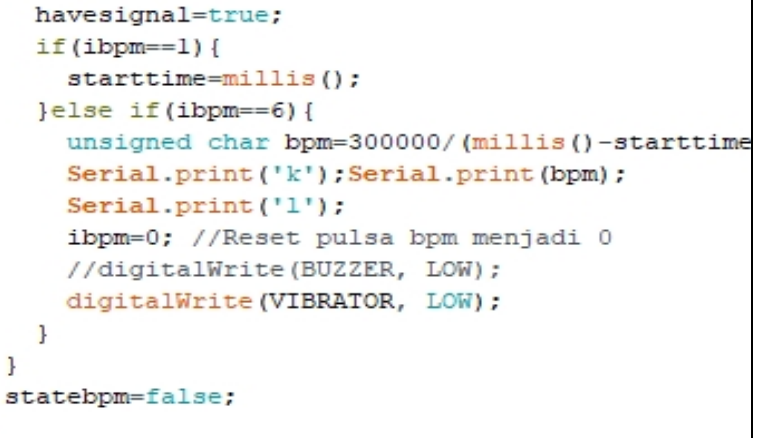

SNIPPET CODE 3 serves to calculate the heart rate per minute by calculating the time it takes for every five waves. From the five waves, the average time needed in one wave is taken. The time in one wave is multiplied by 60 seconds to get BPM (Beat Per Minute). The BPM value is then sent to the computer, separated by the characters $\mathrm{k}$ and 1 .

SNIPPET CODE 4. Send the ADC data and codes

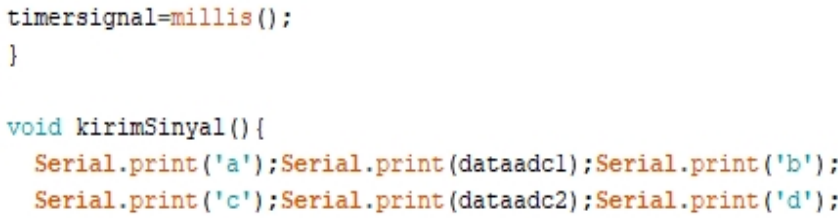

SNIPPET CODE 4 serves to send infrared signals and LED red lamps to be displayed to the computer. The LED Red lamp signal is separated by characters a and $b$, while the Infrared signal is separated by characters $\mathrm{c}$ and $\mathrm{d}$ to differentiate so that the signal is not mixed.

SNIPPET CODE 5. Sending the vibrator code

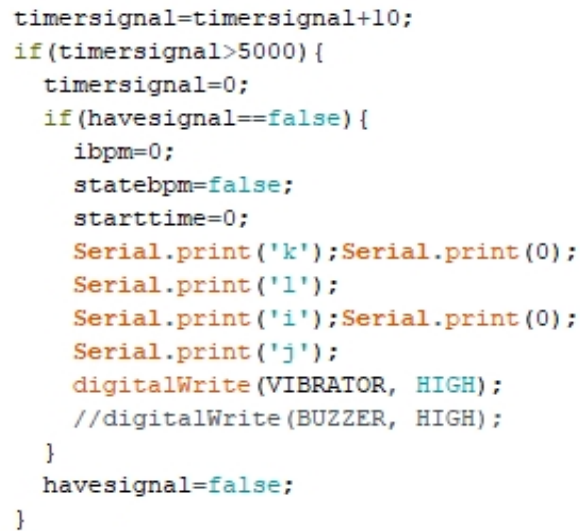


module measurement of respondents (subjects) produce the largest BPM error value of $4.54 \%$ and the lowest $1.49 \%$. In comparison, the results of the measurement of the $\mathrm{SpO}_{2}$ value obtained the highest error value of $2.02 \%$ and the lowest $1.01 \%$. Measurements are carried out using the after-only design method; namely, the author only sees the results without looking at the previous situation. This study has been compared with research conducted by I Dewa Gede Wirayuda and shows that the use of a finger sensor is better used to measure apnea than using a flex detector whose value changes because if the sensor belt shifts [21].

\section{CONCLUSION}

Based on the results of the discussion, this research has produced an apnea monitor design that can detect $\mathrm{SpO} 2$ parameters, alarms, and vibration stimulation. The module can display the values of the two parameters that have been processed by the Arduino program, where the data is sent via Bluetooth and displayed on a computer application. The vibrating motor can also function as a substitute for tactile stimulation and is active when the sensor is released, and the $\mathrm{SpO}_{2}$ shows $0 \%$. The application on the computer that has been made can function properly to display data that has been received from the microcontroller, and the alarm on the computer is also active and sounds when apnea occurs. This research can be implemented on patient monitors to improve patient safety and reduce the workload of nurses or doctors.

\section{REFERENCE}

[1] K. Kesavan and E. B. Gauda, "Neonatal apnea," 5-Minute Pediatr. Consult. 8th Ed., vol. 77, pp. 630-631, 2018, doi: 10.2223/jped.223.

[2] M. Marfuah, W. Barlianto, and D. Susmarini, "Faktor Risiko Kegawatan Nafas Pada Neonatus Di Rsd. Dr. Haryoto Kabupaten Lumajang Tahun 2013," J. Ilmu Keperawatan, vol. 1, no. 2, p. pp.119127, 2013.

[3] J. Zhao, F. Gonzalez, and D. Mu, "Apnea of prematurity: From cause to treatment," Eur. J. Pediatr., vol. 170, no. 9, pp. 1097-1105, 2011, doi: 10.1007/s00431-011-1409-6.

[4] World Health Organization, "Core Medical Equipment - Information," Core Med. Equipments-Information, vol. 11.03, no. http://www.who.int/medical_devices/en/index.html, pp. 36, 37, 2011.

[5] U. Krishnaswamy, A. Aneja, R. Kumar, and T. Kumar, "Utility of portable monitoring in the diagnosis of obstructive sleep apnea," Journal of Postgraduate Medicine. 2015, doi: 10.4103/00223859.166509 .

[6] A. I. Masoud, P. P. Patwari, P. A. Adavadkar, H. Arantes, C. Park, and D. W. Carley, "Validation of the medibyte portable monitor for the diagnosis of sleep apnea in pediatric patients," J. Clin. Sleep Med., 2019, doi: $10.5664 /$ jcsm.7764.

[7] D. Sommermeyer, D. Zou, L. Grote, and J. Hedner, "Detection of sleep disordered breathing and its central/obstructive character using nasal cannula and finger pulse oximeter," J. Clin. Sleep Med., 2012, doi: $10.5664 / \mathrm{jcsm} .2148$

[8] D. Jain, C. D'Ugard, J. Bello, E. Bancalari, and N. Claure, "Hypoxemia Episodes during Day and Night and Their Impact on Oxygen Saturation Targeting in Mechanically Ventilated Preterm Infants," Neonatology, 2017, doi: 10.1159/000481395.

[9] C. D. Trop and L. V. Simon, "Pulse Oximetry," Vet. Anesth. Pain Manag. Secrets, pp. 1-26, 2019, doi: 10.1378/chest.95.4.713.

[10] N. H. Hillman and H. S. Lam, "Respiratory Disorders in the Newborn," in Kendig's Disorders of the Respiratory Tract in Children, 2019.

[11] M. A. D'Agostino, "Obstructive Sleep Apnea, Diagnosis, Management, and Treatment," Otolaryngologic Clinics of North America. 2016, doi: 10.1016/j.otc.2016.10.001.

[12] B. R.B. et al., "Rules for scoring respiratory events in sleep: Update of the 2007 AASM manual for the scoring of sleep and associated events," J. Clin. Sleep Med., 2012.

[13] R. Brugarolas et al., "Wearable SpO2 and Sleep Posture Monitoring System for Obstructive Sleep Apnea Patients," IEEE Trans. Inf. Technol. Biomed., 2015.

[14] A. S. L. Ng, T. K. S. Wong, M. D. I. Gohel, W. W. M. Yu, J. W. Y Chung, and K. L. Fan, "Using pulse oximetry level to indicate the occurrence of sleep apnoea events," Stud. Health Technol. Inform. vol. 122, pp. 672-675, 2006.

[15] J.-L. Pépin et al., "Obstructive Sleep Apnea patients adhering to Continuous positive Airway Pressure: A randomized trial," Chest, 2020.

[16] R. Ristanto and A. Zakaria, "Hubungan Respiratory Rate (RR) dan Oxygen Saturation (SpO2) Pada Klien Cedera Kepala," J. Kesehat. Hesti Wira Sakti, vol. 5, no. 2, pp. 85-90, 2019.

[17] M. Bsoul, H. Minn, and L. Tamil, "Apnea MedAssist: Real-time sleep apnea monitor using single-lead ECG," IEEE Trans. Inf. Technol. Biomed., vol. 15, no. 3, pp. 416-427, 2011, doi: 10.1109/TITB.2010.2087386.

[18] G. Gonzalez-Briceno, J. E. Medow, S. Ortega-Cisneros, D. LoriasEspinoza, A. Minor-Martinez, and J. G. Webster, "Design and Evaluation of a USB Isolator for Medical Instrumentation," IEEE Trans. Instrum. Meas., vol. 68, no. 3, pp. 797-806, 2019, doi: 10.1109/TIM.2018.2853319.

[19] S. Alqassim, M. Ganesh, S. Khoja, M. Zaidi, F. Aloul, and A. Sagahyroon, "Sleep Apnea Monitoring Using Mobile Phones," pp. 443-446, 2012.

[20] D. L. D. Olvera, D. S. Lopez, M. A. M. Prado, J. R. Resendiz, and Y. O. Rivera, "Noninvasive monitoring system for early detection of apnea in newborns and infants," IECBES 2016 - IEEE-EMBS Conf. Biomed. Eng. Sci., pp. 494-498, 2016, doi: 10.1109/IECBES.2016.7843500.

[21] Y. Y. Lin, H. T. Wu, C. A. Hsu, P. C. Huang, Y. H. Huang, and Y. L. Lo, "Sleep Apnea Detection Based on Thoracic and Abdominal Movement Signals of Wearable Piezoelectric Bands," IEEE $J$ Biomed. Heal. Informatics, vol. 21, no. 6, 2017, doi 10.1109/JBHI.2016.2636778.

[22] I. D. M. Wirayuda, I. D. Gede, H. Wisana, and P. C. Nugraha, "Apnea Monitor based on Bluetooth with Android Interface I Dewa Made Wirayuda, I Dewa Gede Hari Wisana , Priyambada Cahya Nugraha," vol. 1, no. 2, pp. 50-56, 2019, doi: 10.35882/ijeeemi.v1i2.1. 